\title{
MOVING LOAD IDENTIFICATION WITH LONG GAUGE FIBER OPTIC STRAIN SENSING
}

\author{
QINGQING ZHANG ${ }^{1}$, WENJU ZHAO ${ }^{2}$, JIAN ZHANG ${ }^{2 *}$ \\ ${ }^{1}$ School of Civil Engineering, Sichuan Agricultural University, \\ Dujiangyan 611830, China \\ ${ }^{2}$ Jiangsu Key Laboratory of Engineering Mechanics, Southeast University, \\ Nanjing 210096, China
}

Received 17 November 2020; accepted 16 March 2021

\begin{abstract}
Moving load identification has been researched with regard to the analysis of structural responses, taking into consideration that the structural responses would be affected by the axle parameters, which in its turn would complicate obtaining the values of moving vehicle loads. In this research, a method that identifies the loads of moving vehicles using the modified maximum strain value considering the long-gauge fiber optic strain responses is proposed. The method is based on the assumption that the modified maximum strain value caused only by the axle loads may be easily used to identify the load of moving vehicles by eliminating the influence of these axle parameters from the peak value, which is not limited to a specific type of bridges and can be applied in conditions, where there are multiple moving vehicles on the bridge. Numerical simulations demonstrate that the gross vehicle weights (GVWs) and axle weights are estimated with high accuracy under complex vehicle loads. The effectiveness of the proposed method was verified through field testing of a continuous girder bridge. The identified axle weights and gross vehicle weights are comparable with the static measurements obtained by the static weighing.
\end{abstract}

Keywords: axle parameters, influence line theory, long gauge strain, maximum strain, moving load identification.

\footnotetext{
* Corresponding author. E-mail: jian@seu.edu.cn

Qingqing ZHANG (ORCID ID 0000-0001-5695-8558)

Wenju ZHAO (ORCID ID 0000-0003-2892-390X)

Jian ZHANG (ORCID ID 0000-0002-9129-255X)

Copyright (c) 2021 The Author(s). Published by RTU Press

This is an Open Access article distributed under the terms of the Creative Commons Attribution License (http://creativecommons.org/licenses/by/4.0/), which permits unrestricted use, distribution, and reproduction in any medium, provided the original author and source are credited.
} 


\section{Introduction}

In view of the inconveniences caused by stop detection required by the Weigh-in-Motion (WIM) systems for overload detection on highways, the moving vehicle load identification based on the bridge, which can be used to estimate vehicle loads conveniently, is becoming a topical issue in structural identification (Rahbari et al., 2015; Meng et al., 2019; Tang et al., 2020; Chen et al., 2020). The Bridge Weigh-in-Motion (B-WIM) is capable of providing accurate measurements of the vehicle type, size and weight from the recorded bridge responses (Dunne et al., 2005; Jacob et al., 2010; Gonzalez et al., 2012; Zhao et al., 2016). There are two kinds of B-WIM systems, namely, the axle-detector system and the Free-of-Axle-Detector (FAD) system. The axle-detector system consists of tape switches measuring vehicle speed and axle spacing installed in the pavement, and strain gauges on the bottom flanges of the girders measuring structural flexural strain. Taking into consideration that the tape switches degrade within short periods of use, in the FAD systems, strain sensors are installed on the bottom of the bridge girders. The strain sensors are either exclusively used for axle detection or as a part of the overall B-WIM measurement system (Žnidarič et al., 2002). However, it is worth noting that the available FAD systems can only be applied to the bridges, which demonstrate sharp peaks in flexural strain responses, such as short span bridges with cross beams (Kalin et al., 2006). In order to overcome this limitation, a new methodology of axle detection is being investigated, including the use of visual systems (Caprani et al., 2013), development of shear strain sensors (Bao et al., 2016), the virtual simply supported beam method and the virtual axle method (He et al., 2017, He et al., 2019). A B-WIM method that only uses several long-gauge fibre Bragg grating (FBG) has been proposed to solve the issues of sensor feasibility, inapplicability for multiple vehicle scenarios and the need for an additional axle-detector (Chen et al., 2019). Still, more research is needed to improve the reliability of these technologies.

Many methods for moving force identification were proposed in the past decades. The classical time domain method and frequency time domain method were developed to identify the moving load on the bridge. Later, the regularization method was introduced (Chan et al., 2001; Law et al., 2001). Various methods have been developed on the basis of regularization, such as superposition and regularization mode, first-order Tikhonov regularization and dynamic programming, the updated static component technique, and Tikhonov regularization method combined with the moving average concepts (Zhu et al., 2006; González et al., 2008; Pinkaew and Asnachinda, 2007; Pan et al., 2017). 
Some researchers suggest using vehicle-bridge coupling in identification of moving loads. For example, a simply supported Bernoulli beam model and a vehicle system with 4 degrees-of-freedom were used in Identification With Long Gauge Fiber Optic Strain Sensing a stochastic force identification algorithm, taking into consideration the influence of pavement roughness (Wu and Law, 2001). Within the method of identifying vehicle parameters using the glowworm swarm optimization algorithm (GSO), the vehicle system of 2-DOF with 5 parameters and 4-DOF with 12 parameters were used to solve the objective function of the optimization problem (Li et al., 2016). Based on the influence line theory and distributed optical fiber sensing technique, a method to obtain the load of a single truck has been developed (Yang et al., 2016). A local linear embedding algorithm is used to identify continuous or discontinuous loads from the response data (Zhang et al., 2019). Combining machine vision and weigh-in-motion monitoring information, a method to identify the real time distribution of the actual vehicle queue has been suggested (Ge et al., 2020). Wang et al. suggest identifying moving train load parameters using the enhanced classic moving force identification method (Wang et al., 2019). In order to simultaneously identify structural performance and moving load, some researchers have attempted to put forward a finite element model updating method based on the dynamic response sensitivity, a Bayesian inference regularization method, and so on (Lu and Liu, 2011; Feng et al., 2015; Shahbaznia et al., 2020). Many sensing technologies have also been developed and used for the identification of moving load, such as piezoelectric sensors, FBG sensors and camera machine vision (Zhang et al., 2021; Alamandala et al., 2021, Dan et al., 2019). Most of these studies use bridge responses to identify the moving vehicle loads, however, the moving vehicle loads are not easily detectable, because different axle parameters of the vehicles would have an effect on the bridge responses even though the vehicle loads are the same. In addition, most of the above-mentioned methods are only applicable for load identification of a single vehicle.

The advent of fiber optic sensing strategies, especially introduction of Fiber Bragg Grating (FBG) sensors, has ensured certain degree of flexibility and practicality in moving load identification, where the conventional sensors may not be used, since they are either incapable or not applicable in order to make reliable measurements. Unlike conventional point-based FBG sensors, the long-gauge FBG sensing technology can be extended from a few centimeters to a few meters thanks to special design and fabrication. The long-gauge FBG sensor with an improved packaging design can enhance the measuring sensitivity when the strain response is very small or environmental noise is strong. The distributed long-gauge FBG sensors are used for area sensing to 
collect distributed information about the key structural elements or crucial areas. Their use not only allows saving on the cost of sensors, but also provides sufficient data for effective SHM (Li et al., 2007; Zhang et al., 2017).

The objective of this article is to develop a method for identifying GVWs by eliminating the influence of axle parameters on the structural response. The proposed method implies using the long-gauge FBG sensing technology employing its advantages - the fact that it allows measuring the distributed strain responses at least throughout the most important areas of the structures. The method of considering the modified maximum strain caused only by axle loads based on the influence line (IL) theory is proposed, in which the measured longgauge strain data are used for identification of GVWs and axle weights of the moving vehicles. The article is structured as follows: In Section 2 , the concept of long-gauge strain is introduced and the theoretical substantiation of the proposed method is provided considering such issues as estimation of axle spacing and axle weight ratios, modification of the maximum strain value, as well as identification of GVWs and axle weights. Section 3 provides numerical examples, verifying the feasibility of the proposed method. Description of the field tests and obtained results are provided in Section 4 to verify the effectiveness of the proposed method. Conclusions are presented in Section 5.

\section{Method for moving vehicle load identification}

In this section, the implementation of the modified maximum strain based on the influence line theory to solve the problems related to moving vehicle load identification is described. The method can be used for all bridge types and is applicable in conditions with multiple passing vehicles. The strain time history and the maximum strain value are separately employed in the proposed method. The strain time history is considered to estimate the number of axles, axle spacing, axle weight ratio and other axle parameters. The maximum strain value is used to identify the GVWs. Because the parameters of the axle spacing and the axle weight ratios from different moving vehicles have an impact on the maximum strain values, the contributing factors and the axle load pattern are then determined in order to modify the maximum strain values. Comparing with the modified maximum strain value in the calibration test, the GVWs and the axle weights of each vehicle are determined combining the estimated axle parameters. The flow chart in Fig. 1 schematically represents the proposed method. 


\subsection{The Long-gauge Strain}

As mentioned previously, most strain sensors used for moving load identification described in the literature are point-type sensors, which are too local to reveal inherent structural characteristics. Even the widely used FBG-based strain sensor characterized by such promising features as high precision level, stable sensing capacity and reliability (Bocciolone et al., 2013; Zhang et al., 2015; Zhang et al., 2020) is still categorized into the group of point sensors due to its short gauge length. The recently developed distributed sensing technologies such as the Brillouin Optical Time Domain Reflectometry (BOTDR) also have limited properties and high costs. Therefore, the long-gauge FBG sensors are used in the field test of the studied bridge, because they can be extended to several centimeters or meters through a special design and manufacturing ( $\mathrm{Li}$ and $\mathrm{Wu}, 2007$ ). The principle feature of these sensors is a bare optic fiber with the FBG sleeved in an embedded tube and fixed at two ends to ensure that the measured value represents the average
Moving Load Identification With Long Gauge Fiber Optic Strain Sensing

\section{Axle parameters estimation}

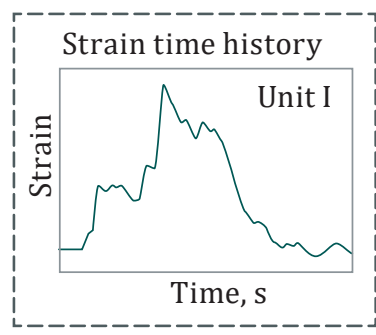

Calobration test
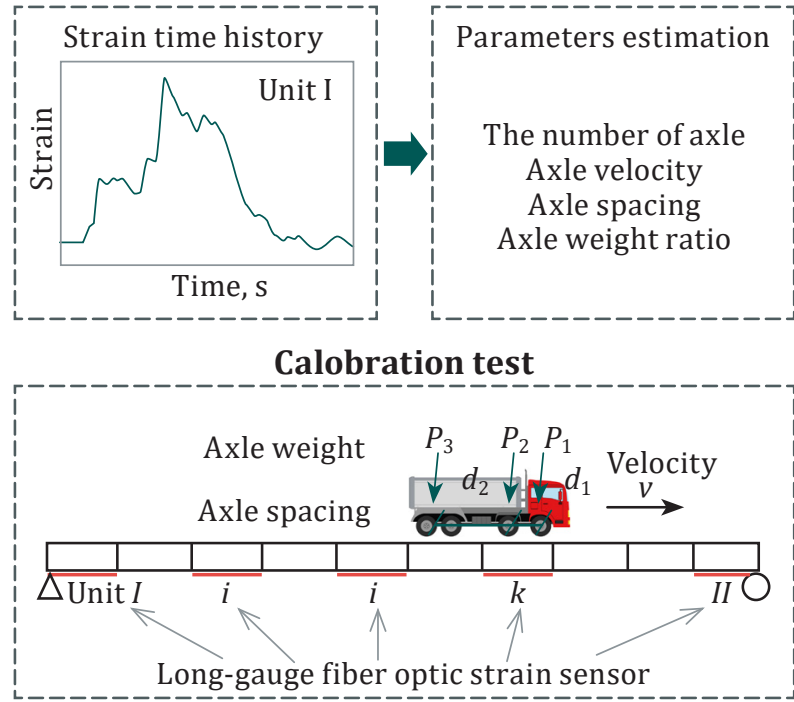

Moving load identification
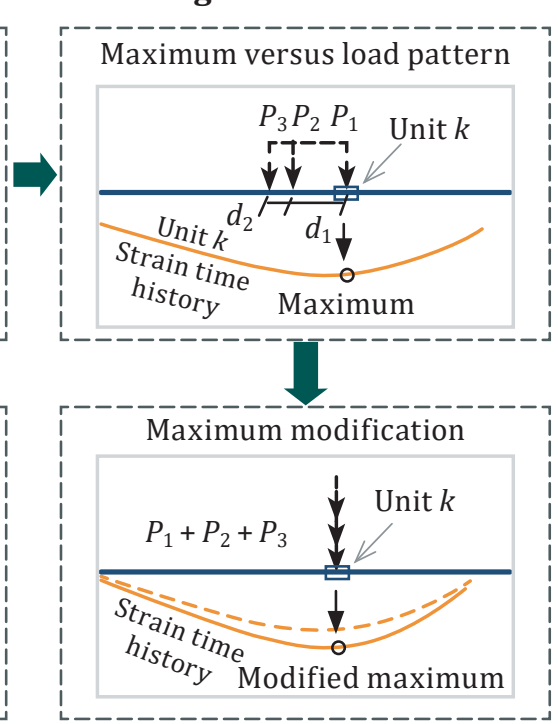

Identification of moving loads, including the estimation of the number of axle, axle spacing, axle velocity, GVW's and the axle weights

Figure 1. Flow chart of the proposed method: Long-gauge Fiber Optic Strain Sensing 
strain over the gauge length. Figure 2 shows the manufacturing and the features of the long-gauge FBG sensor. The strain measured by the long-gauge sensors will be the average strain over the long-gauge length. Multiple sensing units can be connected in series to cover a key sensing area. Then multiple key areas are connected to form a distributed sensing network for structural area macro-strain measuring.

The long-gauge sensor allows measuring static/dynamic structural strain related to structural rotations with high precision. For a beam element with two local DOF's (vertical translation $v$ and rotation $\theta$ ) at each node, the long-gauge strain (macro strain) measurement in the sensing unit $j$ can be defined as

$$
\varepsilon_{j}(t)=\mu_{j}\left[\theta_{o}(t)-\theta_{p}(t)\right]
$$

where $\mu_{j}=h_{j} / L_{j}, h_{j}$ is the distance from the sensor to the neutral axis of the beam, $L_{j}$ is the length of the sensing unit $j ; \theta_{o}(t)$ and $\theta_{p}(t)$ are rotations of nodes $o$ and $p$ of the sensing unit $j$ at the time $t$, respectively.

\subsection{Axle parameter estimation}

The proposed method aims to identify the GVWs of moving vehicles without using axle detectors, while the axle information of the moving vehicles necessary for identifying the GVWs is unknown. The estimation of axle parameters, especially axle spacing and axle weight ratio of the moving vehicle, is based on the IL of the instrumented bridge and the strain difference. The first order difference is used to process the strain measurements near the abutments of the bridge.

To identify the basic axle information, the strain time histories measured near the abutments at the entrance and exit of the bridge are utilized. The measurement of the point $m$ at the entrance of the bridge is taken as an example to illustrate the identification of axle weight ratios.
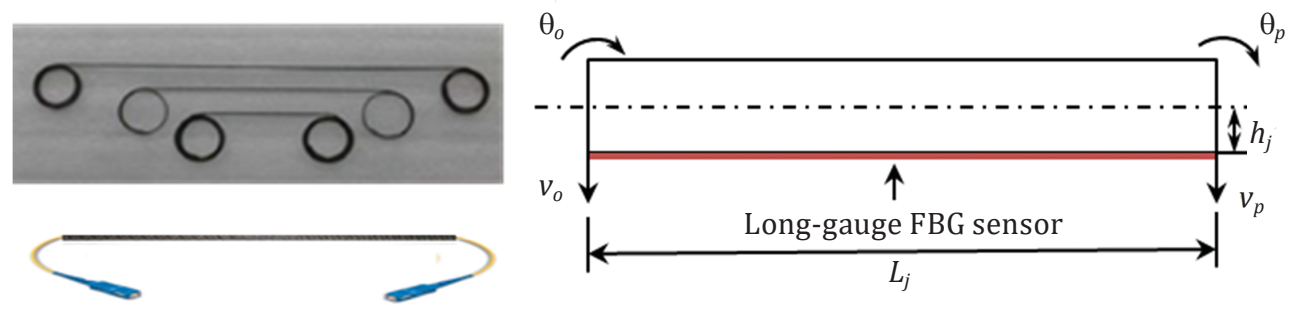

Multiple sensing units connected to from distributed sensing

Figure 2. The long-gauge fiber optic sensor 
For each span of the bridge, the IL of point $m$ is approximately expressed as $\bar{f}_{m}(x)=a_{1} x, x \in\left(0, x_{m}\right)$ and $\bar{f}_{m}(x)=a_{2} x+b, x \in\left(x_{m}, l_{1}\right)$, where $a_{1}, a_{2}$, and $b$ are coefficients of function $\bar{f}_{m}(x)$, respectively, and $x_{m}$ is the distance from support A to point $m$. The strain response at point $m$ is measured with the long-gauge FBG strain sensor, when moving vehicles pass over the bridge. In order to eliminate the trend of the strain response time history, the measured strain time history is processed by the strain difference method. The maximum strain difference values, namely the peak values, of the strain difference time history are obtained, which are expressed as

$\Delta M_{i}=\left\{\left(P_{i+1}+P_{i+2}+\ldots+P_{N}\right) a_{1}+\left(P_{1}+P_{2}+\ldots+P_{i}\right) a_{2}\right\} \Delta x \gamma_{\varepsilon}, i=1,2, \ldots, N$

where $\Delta M_{i}$ is the $i$-th peak value of the strain difference time history; $P_{i}$ is the weight of the $i$-th axle; $\Delta x$ is the distance increment versus $\Delta t ; N$ is the total number of the vehicle axles; $\gamma_{\varepsilon}$ is the coefficient of the moment-strain.

As shown in Fig. 3, point $m$ is located on the second span $\left(l_{1}<m \leq L\right)$ of a two-span continuous beam bridge with a length of $L$, where $l_{1}$ and $l_{2}$ are the lengths of the first and second spans, respectively. The response time history of point $m$ is collected when a tri-axle vehicle passes across the bridge. $\Delta M_{i}$ is obtained by subtracting the strain response of axle $i$ acting on point $m$ from the strain response of axle $i$ acting on point $\Delta x$ away from point $m$. For the simply supported beam bridge, the calculation of $\Delta M_{i}$ can be made directly by using the IL $\bar{f}_{m}(x)$. The IL of the continuous beam bridge consists of the IL $\bar{f}(x)$ and additional bending moment functions shown in Eqs. (9) and (10). It is necessary to analyze the strain difference data in the range from $l_{1}$ to $L$, because $\Delta M_{i}$ belongs to this range. The IL of point $m$ in this range is mainly affected by $\bar{f}(x)$, and this part of IL is calculated by first-order difference to obtain the strain difference data. The value of the additional bending moment functions in this strain difference data is very small and can be approximately ignored. It has been concluded that Eq. (2) applies to simply supported beam bridges as well as continuous beam bridges.

It should be noted that the axle number can be identified by the number of peaks of the strain difference time history. Taking $\Delta M_{N}$ as the reference and dividing $\Delta M_{i}$ by $\Delta M_{N}$, the following relation is obtained:

$$
\begin{aligned}
\frac{\Delta M_{i}}{\Delta M_{N}} & =\frac{P_{1}+P_{2}+\ldots+P_{i}}{G V W}+\frac{\left(P_{i+1}+P_{i+2}+\ldots+P_{N}\right)}{G V W} \frac{a_{1}}{a_{2}}= \\
& =r_{i}+\left(1-r_{i}\right) \frac{a_{1}}{a_{2}} \Delta i=1,2, \ldots, N-1,
\end{aligned}
$$

where $r_{i}=\frac{P_{1}+P_{2}+\cdots+P_{i}}{G V W}, r_{i}$ can be solved and represented as 


$$
r_{i}=\left(\frac{\Delta M_{i}}{\Delta M_{N}}-\frac{a_{1}}{a_{2}}\right) \frac{a_{2}}{a_{2}-a_{1}} .
$$

Assumed that $r_{i}^{\prime}=P_{i} / P V W$, then

$$
r^{\prime}=\left\{\begin{array}{l}
=r_{1}, i=1 \\
r_{i}-r_{i-1}, i \neq(1, N) \\
1-r_{N-1}, i=N
\end{array}\right.
$$

Taking $r_{N}^{\prime}$ as the reference and dividing the $r_{i}^{\prime}(i \neq N)$ by $r_{N}^{\prime}$,

$$
p_{i}=\frac{r_{i}^{\prime}}{r_{N}^{\prime}}=\frac{P_{i}}{P_{N}},
$$

where $p_{i}$ is the axle weight ratio of the $i$-th axle to the $N$-th axle (reference axle).

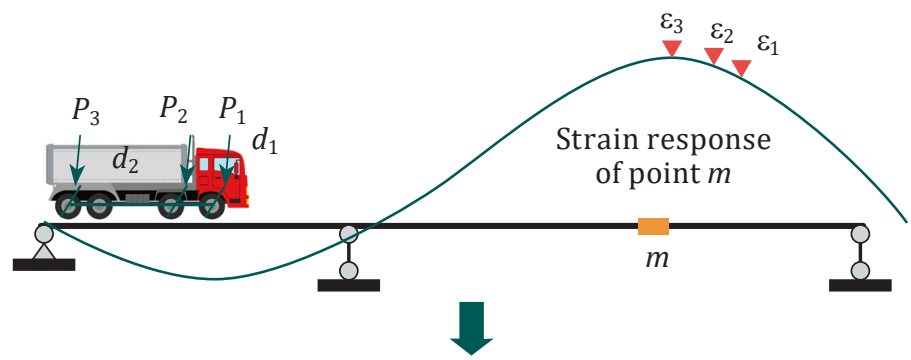

The peak of strain difference time history

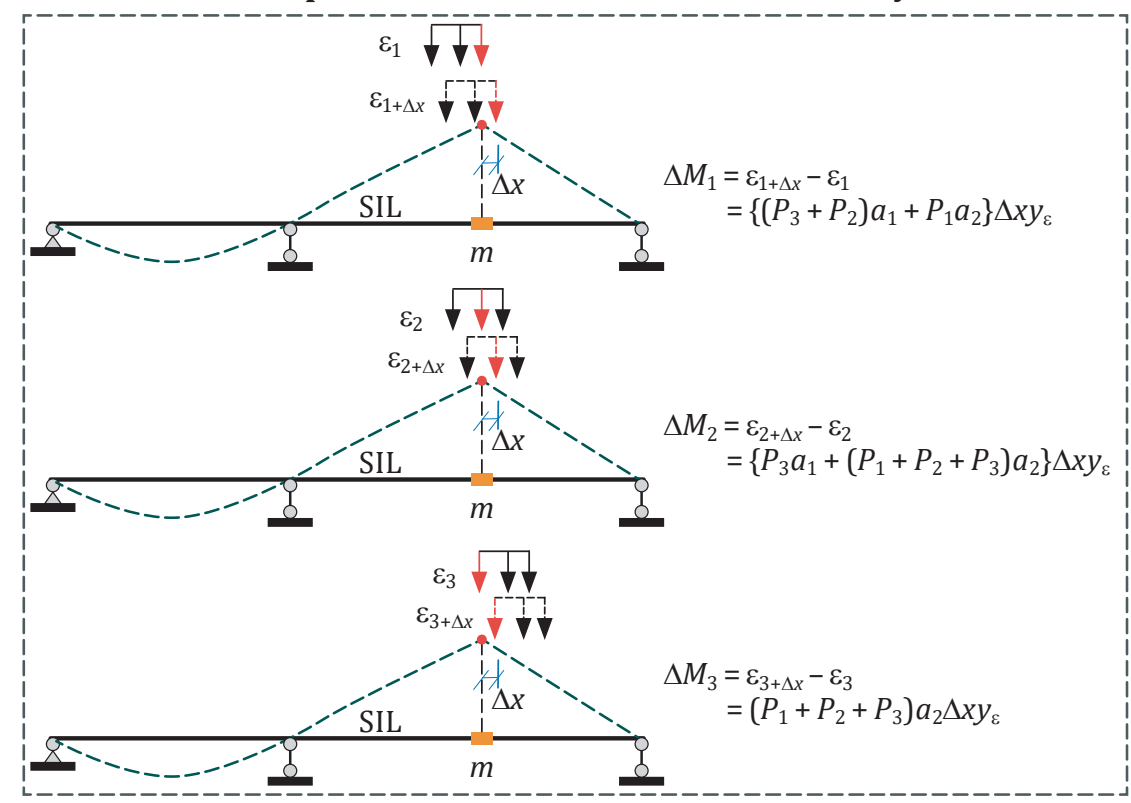

Figure 3. The schematic diagram of $\Delta M_{i}$ 
From Eq. (3) to Eq. (6), it is known that all axle weight ratios of the Identification With Long Gauge moving vehicles are obtained from the peaks of the strain difference time history. In addition, the axle spacing and axle weight parameters Fiber Optic Strain Sensing from various vehicle types, including different axle numbers are investigated for eliminating the false peaks on the strain difference time history, and the following conclusions are drawn: each vehicle has two and more axle sets, and each axle set includes at least one axle. The first axle set of all vehicle types has only one axle, and except that the number of the first axle set is one, the number of the following axle set is equal to or greater than two. For a certain axle set, the axle spacing is in the range from $1.2 \mathrm{~m}$ to $1.5 \mathrm{~m}$. Thus, it is determined that the peaks of the axle spacings are also in this range for this axle set. After identifying the axle weight ratios, the velocity of the vehicle passing on each sensing unit is estimated as

$$
v_{j}^{V}=v^{C} \frac{t_{j}^{C}}{t_{j}^{V}}, j=1,2, \ldots, n,
$$

where $v^{c}$ is the velocity of the pre-weighed truck in the calibration test; $t_{j}^{c}$ and $t_{j}^{V}$ are the times corresponding to the maximum value of the measured strain of the sensing unit $j$ in the calibration and verification tests respectively; $n$ is the total number of sensing units.

When the velocity of the vehicle is assumed to be constant, it can be estimated by the mean values. The time corresponding to the peaks of the strain difference time history is used to identify the axle spacing,

$$
d_{i}=\left(t_{i}^{V}-t_{i-1}^{V}\right) v^{V}, i=2,3, \ldots, N,
$$

where $d_{i}$ is the distance between (i-1)-th axle and $i$-th axle; $N$ is the total number of the vehicle axles; $t_{i}^{V}$ and $t_{i-1}^{V}$ are the times corresponding to $i$-th and (i-1)-th peaks of the strain difference time history, respectively.

\subsection{GVWs and axle weights identification}

\subsubsection{Modification of the maximum strain value}

Axle spacing and axle weight ratios have significant effects on the maximum value of the measured strains. Because the positions of sensing units are different, the axle acting on the peak of the IL to produce the maximum strain is different for each sensing unit, which is defined as the axle load pattern. The truck with three axles used in the calibration test passing across the three-span continuous bridge is studied as an example to illustrate the axle load pattern (Fig. 4). For the verification test, the vehicle spacing and axle load pattern are 
determined by all strain time histories measured by the long-gauge sensors.

It is seen from Fig. 4 that the maximum strains caused by the axles are different when the same vehicle loads act on different positions of the bridge. In order to determine the load axle that causes the maximum strain at different positions on the bridge, the concept of the dividing point is defined. It means that there are $N-1$ dividing points to divide the span into $N$ areas when an $N$-axle vehicle passes over a span of a bridge. For each area, the axle load pattern causing the maximum strain at different positions is the same.

All maximum strain values are extracted from the strain response time histories to determine the axle load pattern. To estimate the load area of the $i$-th axle for each span of the bridge, strains $s_{i}, \varsigma_{i-1}, \varsigma_{i+1}$ are calculated when the $i$-th, $(i-1)$-th and $(i+1)$-th axles act on the peak of the IL respectively. The range of the load area of the $i$-th axle can be obtained when $s_{i}>s_{i-1}$ and $s_{i}>s_{i+1}$. The positions of the dividing points are calculated as

$$
d p_{i}=\frac{\left(p_{i} v_{i}+\cdots+p_{N-1} v_{N-1}+v_{N}\right) L}{p_{1} v_{1}+\cdots+p_{N-1} v_{N-1}+v_{N}}, i=1,2, \ldots, N,
$$

where $d p_{i}$ is the $i$-th dividing point and $v_{i}$ is the velocity of the $i$-th axle. The axle load pattern for the area between the points $d p_{i-1}$ and $d p_{i}$ is the $(i-1)$-th axle that causes the maximum strain. As shown in Fig. 4, when the vehicle with three axles passes over a span of a bridge, there are two dividing points separating the bridge span into three areas.

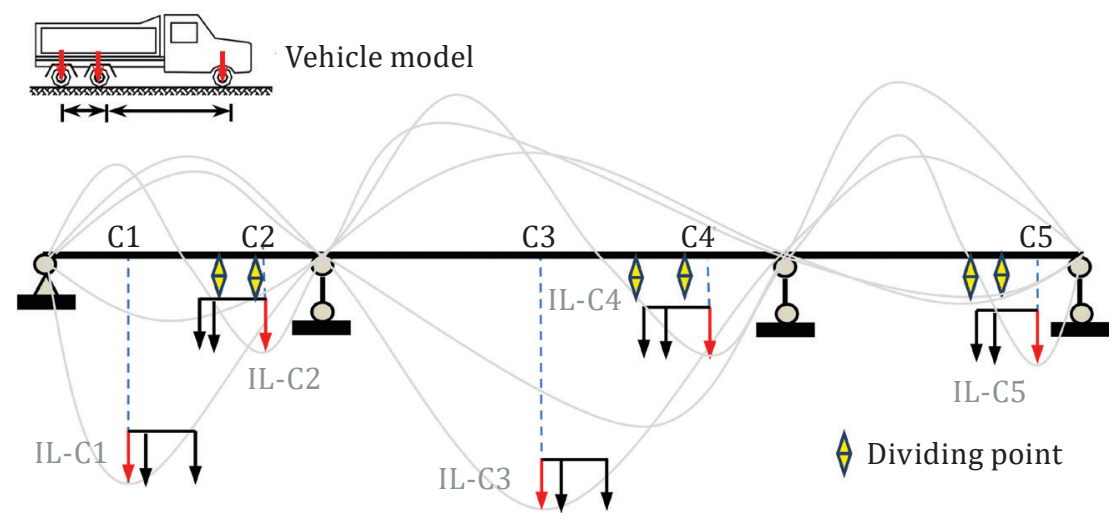

Figure 4. Dividing point distribution and axle load patterns for the threespan continuous bridge 
Sensing unit $j$ from the middle span of the three-span continuous girder bridge is investigated to illustrate the procedure of estimation of the contributing factors. In the mechanical analysis of the continuous Identification With Long Gauge Fiber Optic Strain Sensing girder bridge, each span can be simplified to a simply supported beam and additional bending moment acting on the end of the beam. Thus, the strain IL for the middle span is determined by simply supported beam and additional bending moment. The IL at the sensing unit $j$ can be expressed as

$$
f_{j}(x)=\bar{f}_{j}(x)+f_{j}\left(X_{21}(x), X_{22}(x)\right),
$$

where $f_{j}(x)$ denotes the IL function at the sensing unit $j$ and $\bar{f}_{j}(x)$ is the IL of the sensing unit $j$ contributed by the simply supported beam. $X_{21}(x)$ and $X_{22}(x)$ are the additional bending moment functions when the unit load acts on the 2 nd span. When the axle load pattern of the sensing unit $j$ is the $i$-th axle, the maximum strain of the sensing unit $j$ is calculated as,

$$
\begin{aligned}
\varsigma_{j}= & \frac{\left(P_{1}+\ldots+P_{N}\right)\left\{x_{j}\left(l-x_{j}\right)-f_{j}\left(X_{21}\left(x_{j}\right), X_{22}\left(x_{j}\right)\right)\right\}}{l_{2}} \\
& -\frac{\phi^{\prime}\left(P_{i i}, d_{j j}, x_{j}\right)}{l_{2}}-\frac{\phi\left(P_{i i}, f_{j}\left(X_{21}\left(d_{j j}\right), X_{22}\left(d_{j j}\right)\right)\right)}{l_{2}}
\end{aligned}
$$

where $s_{i}$ is the maximum strain of the sensing unit $j$ when an $\mathrm{N}$-axle vehicle passes over the bridge; $x_{j}$ is the distance from support B to the sensing unit $j ; l$ is the length of the middle span; $\phi^{\prime}\left(P_{i i}, d_{j j}, x_{j}\right)$ is the strain of the simple support beam, which is caused by the axle spacing and the single axle weight, where $P_{i i}(i i \neq i)$ is the $i i$-th axle weight, $d_{j j}(j j=1, \ldots, N-1)$ is the $j j$-th axle spacing; $\phi(\cdot)$ denotes the strain from the additional bending moments caused by the axle spacing and the single axle weight. It may be seen from Eq. (11) that the first term on the right side is only caused by the GVW, and the other terms are caused by the axle spacing and the single axle weight. The axle spacing and the axle weight ratios other than the GVW also have an effect on the maximum strain values of each sensing unit. Therefore, in order to study the effect of axle spacing and axle weight ratios on determination of the GVW, the contributing factors representing their effects should be estimated. It may also be seen from Eq. (11) that the contributing factor $\eta_{j}$ can be calculated by

$$
\eta_{j}=\frac{-\phi^{\prime}\left(P_{i i}, d_{j j}, x_{j}\right)-\phi\left(P_{i i}, f_{j}\left(X_{21}\left(d_{j j}\right), X_{22}\left(d_{j j}\right)\right)\right)}{\left(p_{1}+p_{2}+\cdots+p_{N-1}+1\right)\left\{x_{j}\left(l_{2}-x_{j}\right)-f_{j}\left(X_{21}\left(x_{j}\right), X_{22}\left(x_{j}\right)\right)\right\}} .
$$


Based on the derivation of Eq. (12), it is known that the contributing factor $\eta_{j}$ for the simply supported beam bridge does not include $\phi\left[P_{i i}, f_{j}\left[X_{21}\left(d_{j j}\right), X_{22}\left(d_{j j}\right)\right]\right]$ caused by the additional bending moments and can be expressed as

$$
\eta_{j}=\frac{-\phi^{\prime}\left(P_{i i}, d_{j j}, x_{j}\right)}{\left(p_{1}+p_{2}+\ldots+p_{N-1}+1\right)\left\{x_{j}\left(l_{2}-x_{j}\right)-f_{j}\left(X_{21}\left(x_{j}\right), X_{22}\left(x_{j}\right)\right)\right\}} .
$$

The effects of axle spacing and axle weight ratios can be eliminated from the original maximum strain value based on the calculated contributing factors. Specifically, the modified maximum strain value versus time $t$ which is only caused by the GVWs can be calculated by

$$
\bar{\varepsilon}_{j}=\frac{\varepsilon_{j}}{1+\eta_{j}}
$$

where $\varepsilon_{j}$ and $\bar{\varepsilon}_{j}$ are the original and modified maximum value of the sensing unit $j$, respectively.

\subsubsection{GVWs and axle weight identification}

The modified maximum strain value for each sensing unit in the verification test was compared with the corresponding value in the calibration test to identify the GVW. The GVW of moving vehicles were calculated as

$$
G V W_{j}^{V}=\frac{\bar{\varepsilon}_{j}^{V}}{\bar{\varepsilon}_{j}^{C}} \times G V W^{C},
$$

where $G V W_{j}^{V}$ is the identified GVW on the sensing unit $j$ in the verification test, $G V W^{C}$ is the GVW of the calibrated vehicle; $\varepsilon_{j}^{V}$ and $\varepsilon_{j}^{C}$ are the modified maximum strain values of the sensing unit $j$ in the verification and calibration tests, respectively. Based on the identified GVW, the axle weights are estimated by

$$
P_{i j}=\frac{p_{i}}{p_{1}+p_{2}+\ldots+p_{N}} \times G V W_{j}^{V},
$$

where $P_{i j}$ is the identified axle weight of $i$-th axle on the sensing unit $j$.

\section{Numerical verification}

The proposed identification method described in Section 2 has been verified here through a numerical example. In the verification test, three vehicles are simulated to pass across a simply supported beam with a length of $50 \mathrm{~m}$. The weights of three cars (v1, v2 and $v 3)$ are $190 \mathrm{kN}$, 
$400 \mathrm{kN}, 140 \mathrm{kN}$, respectively. The speed of the first car is $25 \mathrm{~m} / \mathrm{s}$, while Identification that of the other two cars is $23.148 \mathrm{~m} / \mathrm{s}$. The car behind arrived on the bridge one second later than the car in front. The bridge is divided into 20 units, each $2.5 \mathrm{~m}$ in length. Specific vehicle information is shown in

Fig. 5.

\subsection{Axle parameters estimation}

The strain response of all units was collected using the long-gauge FBG sensors under the moving loads. An artificial white noise with a standard deviation of $5 \%$ of the RMS value of the real response was added to the measured responses. The moving average method was used to filter the collected data considering the advantages this method offers: simple calculation, small calculation amount and suitability for real-time processing of non-stationary data. The difference of the filtered strain data of units 1 and 20 near the supports were used for estimating the axle parameters, as shown in Fig. 6(a). Based on Eqs. (7) and (8), the speed, spacing and relative position of axles on the bridge were determined. As seen in Table 1, the percent error of the identification axle spacing was calculated and shown compared with the actual axle spacing. The maximum error was $8.28 \%$, and it occurred on $\mathrm{d}_{1}$ identification of vehicle $v 2$. This is mainly due to the small distance between the front and the middle axle. The identified time interval between each vehicle was $1 \mathrm{~s}$, and when the first vehicle drove off the bridge, the third vehicle started to get on the bridge. So, the load condition was divided into two time periods: The first period is the running period of the first vehicle and the second vehicle, and the end time is the time when the first vehicle completely leaves the bridge. The second period is the running period of the second vehicle and the third vehicle, and the beginning time is the time when the third vehicle starts to get on the bridge.

$v 1$
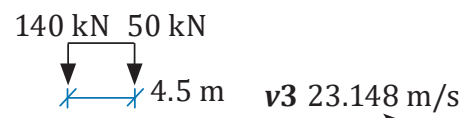

$v 2$

$240 \mathrm{kN} 120 \mathrm{kN} 40 \mathrm{kN}$

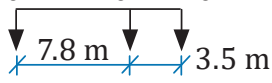

v3
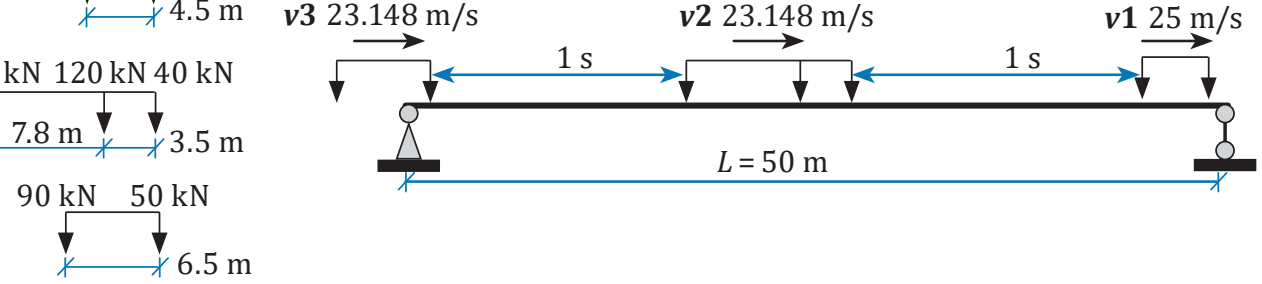

Figure 5. Simulated vehicle information in the verification test 
Table 1. Identified axle spacing versus actual axle spacing

\begin{tabular}{ccccccc}
\hline \multirow{2}{*}{ Vehicle } & \multicolumn{2}{c}{ Identification axle spacing, $\mathbf{m}$} & \multicolumn{2}{c}{ Actual axle spacing, $\mathbf{m}$} & \multicolumn{2}{c}{$\%$ error } \\
& $\boldsymbol{d}_{\mathbf{1}}$ & $\boldsymbol{d}_{\mathbf{2}}$ & $\boldsymbol{d}_{\mathbf{1}}$ & $\boldsymbol{d}_{\mathbf{2}}$ & $\boldsymbol{d}_{\mathbf{1}}$ & $\boldsymbol{d}_{\mathbf{2}}$ \\
\hline$v 1$ & 4.44 & - & 4.5 & - & $-1.33 \%$ & - \\
$v 2$ & 3.79 & 7.69 & 3.5 & 7.8 & $8.28 \%$ & $-1.4 \%$ \\
$v 3$ & 6.89 & - & 6.5 & - & $6 \%$ & - \\
\hline
\end{tabular}

\subsection{GVW and axle weights identification}

To determine the axle load pattern for this load condition, the dividing points were calculated by Eq. (9). The axle parameters in the first time period and the second time period were used to calculate the dividing points of the bridge, respectively. In Fig. $7, \mathrm{dp}_{11}, \mathrm{dp}_{12}, \mathrm{dp}_{13}$ and

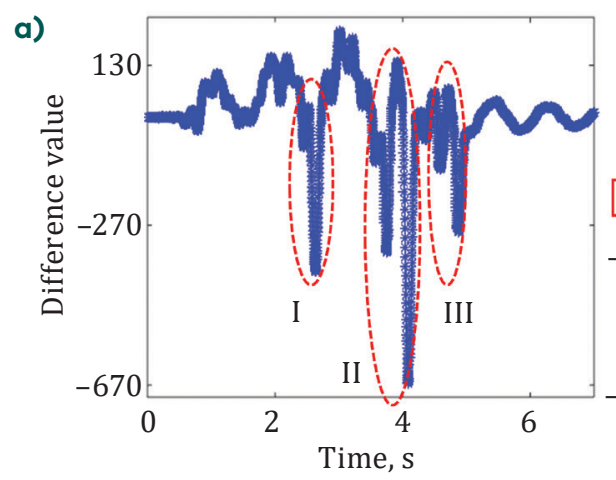

b)

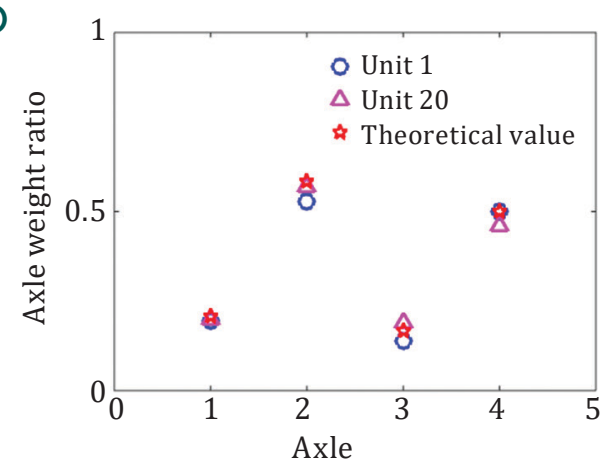

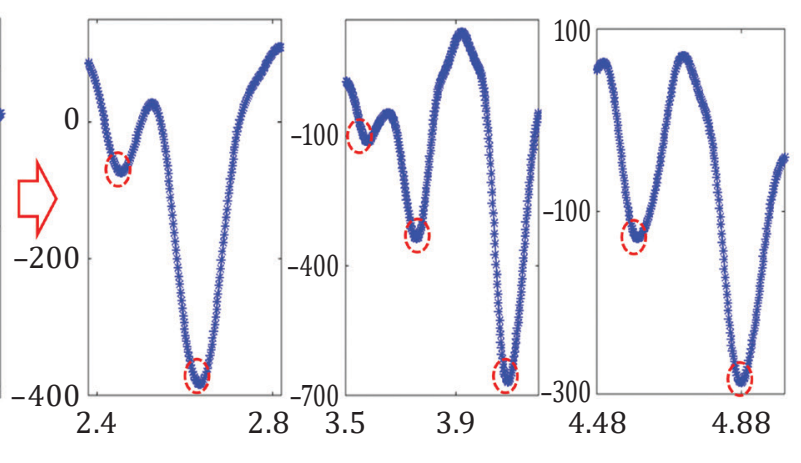

c)

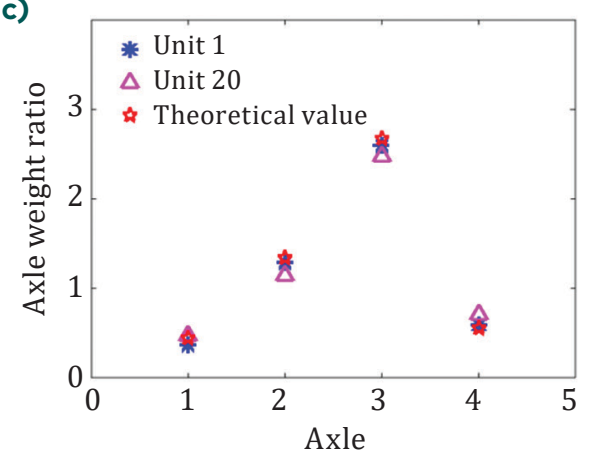

Figure 6. Axle parameter estimation: (a) difference value; (b) axle weight ratio for the first time period; (c) axle weight ratio for the second time period 

first time period, and $d p_{21}, d_{22}, d_{23}$ and $d_{p_{24}}$ are the virtual dividing points based on the axle parameters in the second time period. In the With Long Gauge Fiber Optic Strain first time period, only two vehicles ( $v 1$ and $v 2$ ) act on the beam. The bridge is divided into five areas because of the five axles. For each area, the response time history of the unit was collected, and the maximum value from the response time history corresponds to the specified axle load pattern. For example, the axle load pattern of the maximum value of the unit response in the region between $\mathrm{dp}_{12}$ and $\mathrm{dp}_{13}$ is caused by axle 3 acting on the peak of unit IL. In the second time period, vehicle $v 1$ left the bridge and vehicle $v 3$ entered the bridge. In this time period, there were only vehicle $v 2$ and vehicle $v 3$ on the bridge, which means that there were still five axles acting on the bridge. Therefore, the bride was divided into five areas. Since the two time periods are continuous, the

\section{Virtual dividing points}

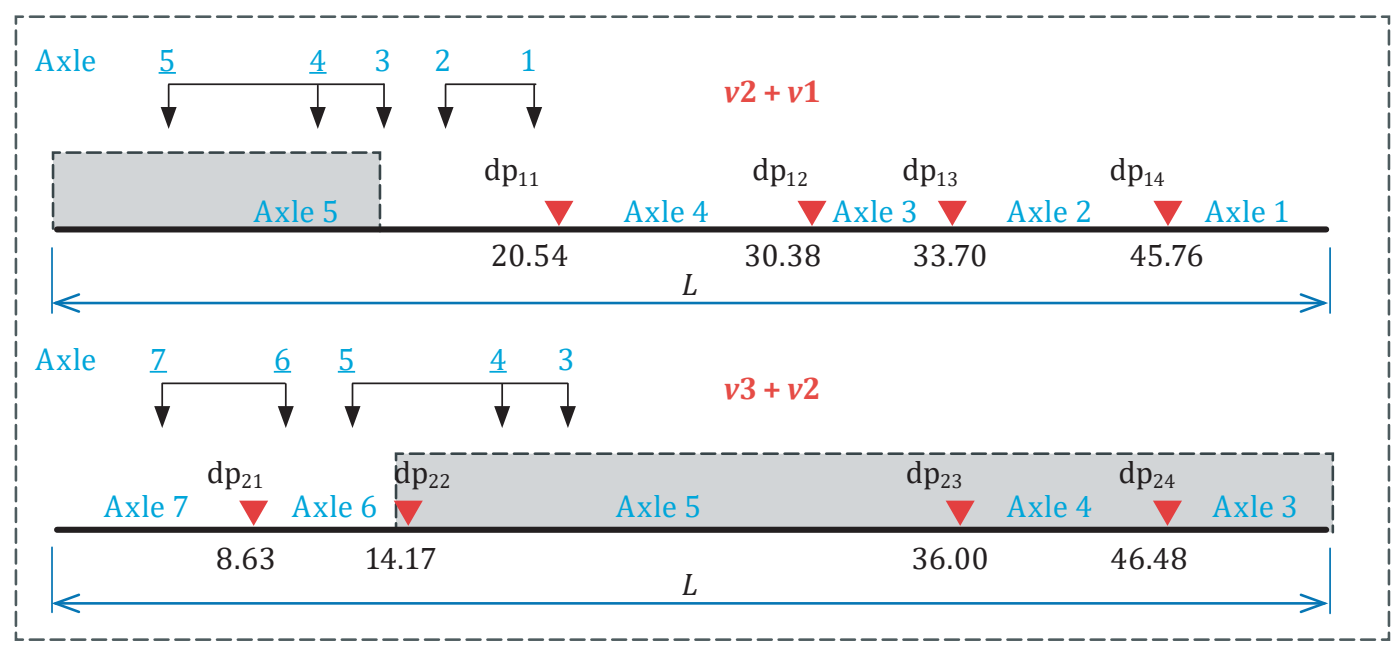

Real dividing points

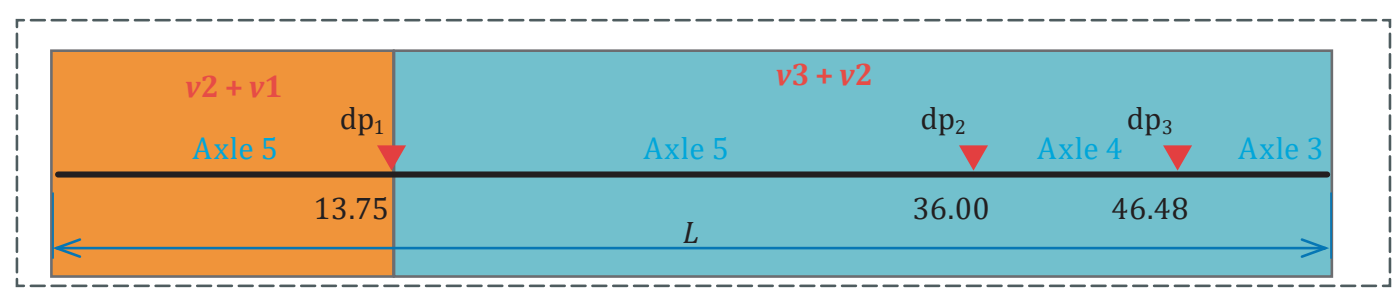

Note: $L$ unit in m.

Figure 7. Dividing points 
gray part on each time period represents the part that is actually used in each time period, and the real dividing points under this condition can be finally determined, as shown in Fig.7. In the area before $d_{1}$, the axle load pattern of the maximum value of the unit response is caused by axle 5 acting on the peak of unit IL under the vehicle loads of $v 1$ and $v 2$. Only vehicles $v 2$ and $v 3$ act on each area after $\mathrm{dp}_{1}$, and the axle load patterns located in these areas are axle 5, axle 4 and axle 3 acting on the peak of the corresponding IL.

The contributing factor for each unit was calculated based on Eq. (13), and Eq. (14) was then used to calculate the modified maximum value only caused by the axle loads, as shown in Fig. 8(a). For the condition of the calibration test, a two-axle vehicle used in this condition had a front axle load of $30 \mathrm{kN}$ and a rear axle load of $50 \mathrm{kN}$ and an axle spacing of $3.5 \mathrm{~m}$, which passes over the bridge at a speed of $13.889 \mathrm{~m} / \mathrm{s}$. The strain time histories were collected by the long-gauge strain sensors and were used to calculate the modified maximum strain value based on the method proposed above. The modified maximum strain value in the verification and calibration test are shown in Fig. 8(b). It may easily be observed that there are obvious differences between the maximum strain before and after modification. Compared with the load of a single vehicle in the calibration test, multiple vehicles in the verification test have a greater impact on the maximum value, especially in the mid-span units.

Since the maximum strain values on units 19 and 20 near the bearings are affected by the vehicles leaving the bridge, they are not applicable for the identification of moving vehicle loads. Eqs. (15) and (16) were used to identify the loads of multiple vehicles in the

a)

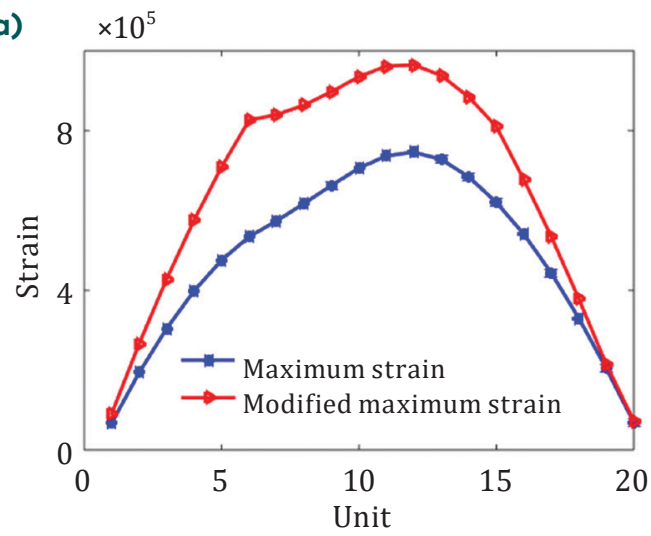

b)

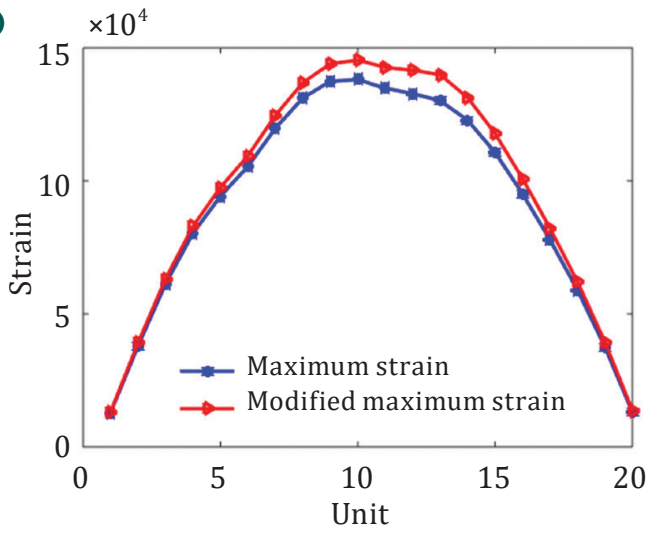

Figure 8. The modified maximum strain: (a) the verification test; (b) the calibration test 
verification test. It is known from the above-presented analysis that the Identification With Long Gauge group of units 1 6, units 1 18 and units 7 18 are used to identify the load of the first, second and third car, respectively. In order to verify the Fiber Optic Strain Sensing effectiveness of the proposed method, the traditional method without considering the influence of the axle parameters on the structural response was compared with the proposed method, which uses the measured maximum value directly. Fig. 9(a) and (b) show the GVW and the axle weight identified with the proposed method, respectively. Compared with the true values of the three cars, the average errors of the identified moving loads are $7.12 \%, 4.69 \%$ and $6.45 \%$, respectively. Estimating the axle weight of each car based on the identified axle weight ratio, the average error of each axle weights identification is
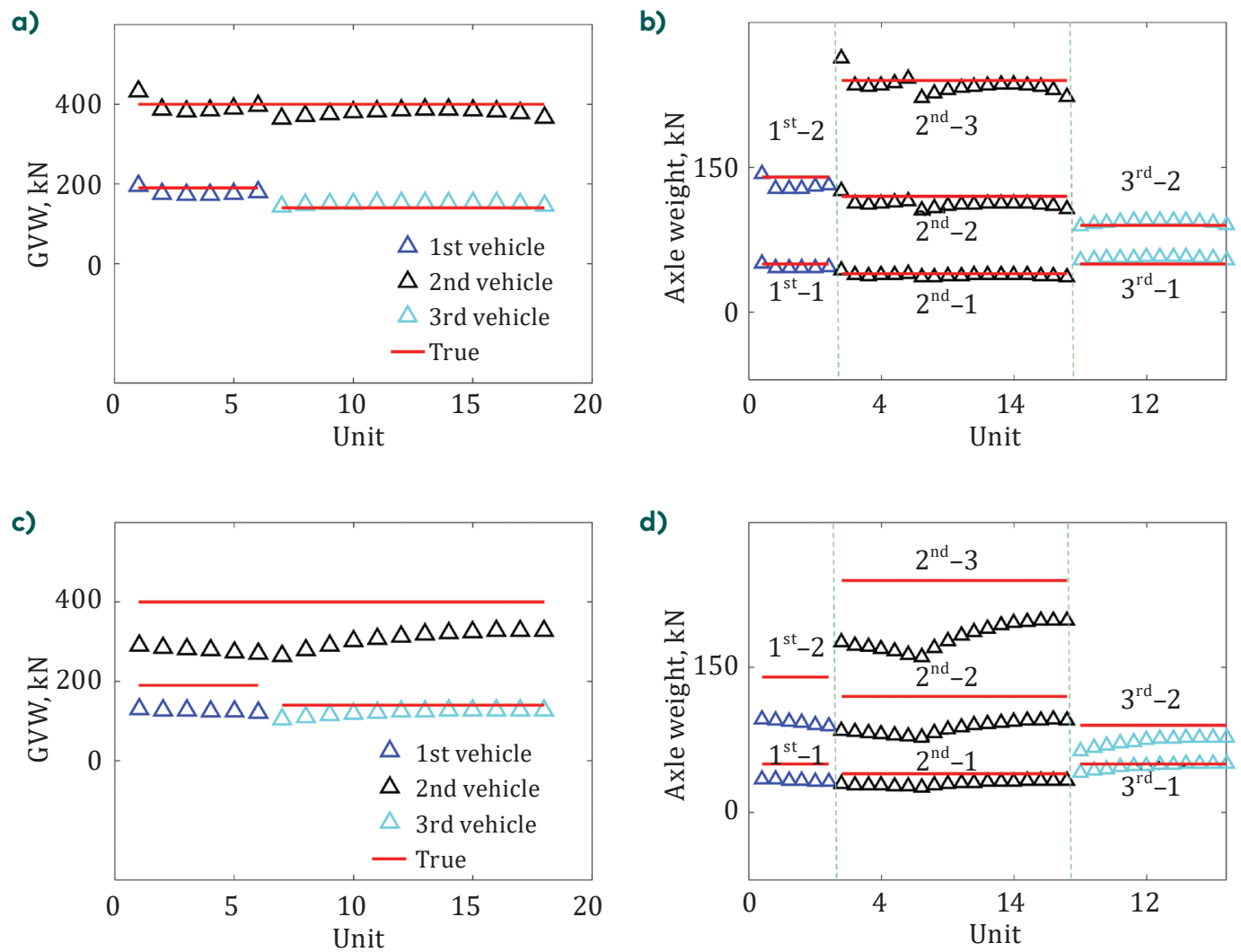

Figure 9. The identified moving loads: (a) the GVWs and (b) the axle weight identified with the proposed method; (c) the GVWs and (d) the axle weight identified with the traditional method 
shown in Table 2. It may be seen from Table 2 that the maximum error is $9.31 \%$ and it occurs in the front axle of vehicle $v 3$. That is mainly due to the fact that the front axle weight of $v 3$ is much lower than the last axle weight of $v 2$. The GVW and the axle weight identified using the traditional method are demonstrated in Fig. 9(c) and (d). For the traditional method, the average errors of the identified moving loads are $33.95 \%, 25.36 \%$ and $13.49 \%$ respectively, and the average errors of identified axle loads are $34.49 \%$ and $33.76 \%$, respectively, for each axle weight identification of $v 1, v 2$, and $v 3$. The average errors of each axle weight identification by the traditional method are shown in Table 2. For the traditional method, the average error of all axle weight identification is $24.27 \%$. But for the proposed method, the average error of all axle weight identification is $6.55 \%$. Compared with the traditional method, the proposed method can effectively obtain the information about the axle weight.

Table 2. The average error of the identified axle weights

\begin{tabular}{ccccccc}
\hline \multirow{2}{*}{ Vehicle } & \multicolumn{3}{c}{ Proposed method, $\%$} & \multicolumn{3}{c}{ Traditional method, \% } \\
& $\boldsymbol{P}_{\mathbf{1}}$ & $\boldsymbol{P}_{\mathbf{2}}$ & $\boldsymbol{P}_{\mathbf{3}}$ & $\boldsymbol{P}_{\mathbf{1}}$ & $\boldsymbol{P}_{\mathbf{2}}$ & $\boldsymbol{P}_{\mathbf{3}}$ \\
\hline$v 1$ & 6.94 & 6.82 & - & 34.49 & 33.76 & - \\
$v 2$ & 4.97 & 6.98 & 3.62 & 25.74 & 27.23 & 24.36 \\
$v 3$ & 9.31 & 2.01 & - & 9.19 & 15.91 & - \\
\hline
\end{tabular}

\section{Verification using field-test data}

\subsection{Description}

The investigated structure is a pre-stressed concrete continuous boxgirder bridge consisting of three spans with a full length of $191.0 \mathrm{~m}$, as shown in Fig. 10(a) and (b). Eighteen long-gauge FBG strain sensors with the gauge length of $1.0 \mathrm{~m}$ were installed on the top side of the bottom plate of the concrete box-girder to measure structural strain responses, as shown in Fig. 10(a) and (c). In the field testing, two kinds of tests were conducted, namely, the calibration test and the verification test. The sampling frequencies of the two cases were set to be $500 \mathrm{~Hz}$. One truck was adopted for the calibration test - a pre-weighed truck with the gross weight of 30 tons $(300 \mathrm{kN})$ crossing over the continuous girder bridge with a slow speed of approximately $5 \mathrm{~km} / \mathrm{h}$. The weights of front, middle 
and rear axles of the test truck are 6 tons ( $60 \mathrm{kN}), 12$ tons $(120 \mathrm{kN})$, and Identification With Long Gauge 12 tons $(120 \mathrm{kN})$, respectively, and the spaces between front and middle, middle and rear are $4.0 \mathrm{~m}$ and $1.35 \mathrm{~m}$, respectively. The measurements Fiber Optic Strain were performed in the verification test. Two trucks passed over the same lane of the investigated bridge at different speeds, they had the same vehicle parameters as the truck used in the calibration test. The trucks were weighed using static weighing to ensure high accuracy. The operators also accurately measured the axle spacing.

\subsection{Field Test Results}

As previously shown, the verification test was used to prove the effectiveness of the proposed system. In the verification test, the axle spacing and axle weight ratios had to be identified first. In order to estimate the contributing factors, the vehicle spacing and the loading vehicles causing the maximum strain were then determined considering all strain time histories. Finally, the maximum strain caused only by the GVW was calculated to identify the GVW and axle weights.

a)
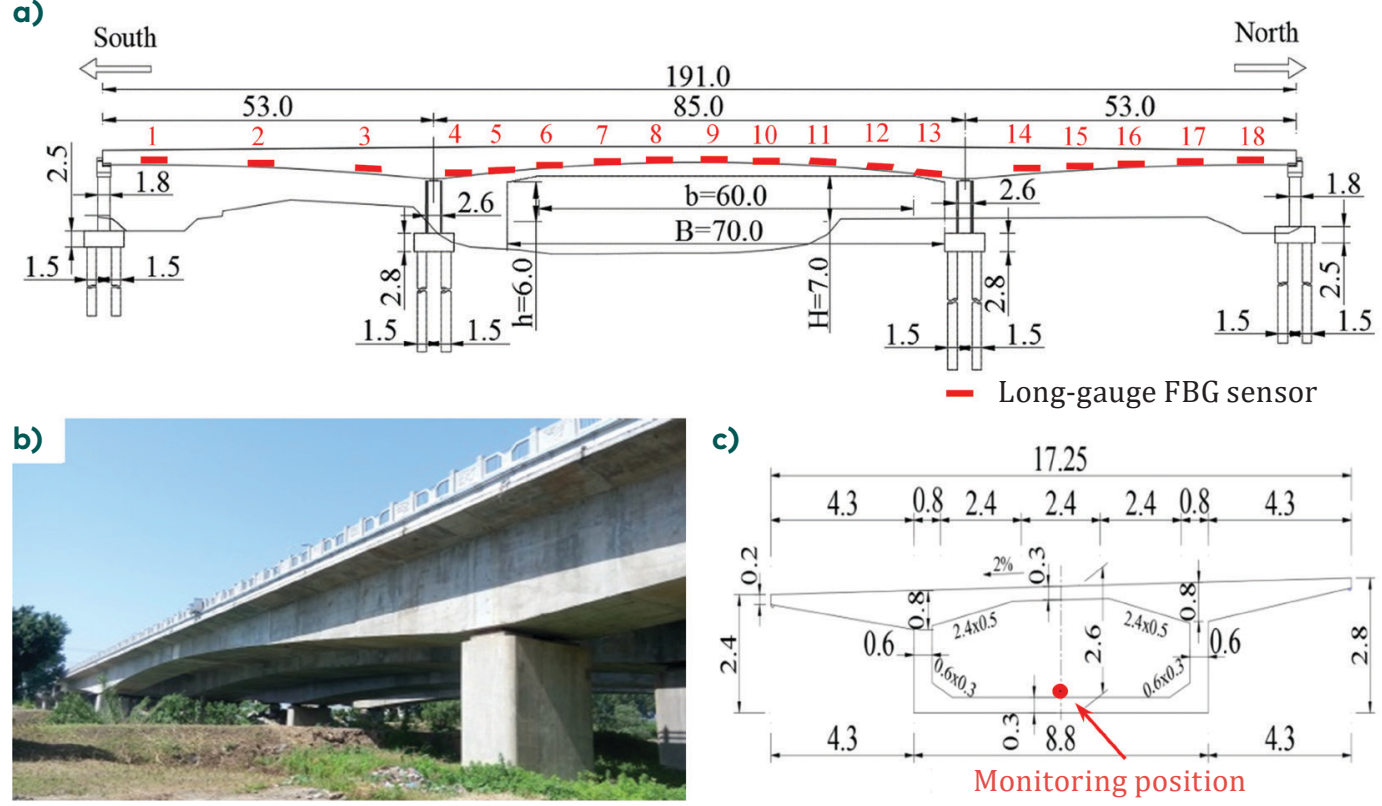

Note: units in $\mathrm{m}$.

Figure 10. Sensor layout and field test: (a) the sensor layout; (b) bridge photo; (c) typical cross-section 


\subsubsection{Axle Parameters Estimation}

The collected data were first filtered to eliminate random fluctuations in the dynamic test data by using the moving average method. The strain measurements from sensors 1 and 18 were used to identify the axle spacing and axle weight ratios. By using the strain difference to process the measured strain time histories, the strain difference time history data can be obtained, as shown in Fig. 11. In Fig. 11(a) and (b), two peaks can be easily found from the difference time history data of sensors 1 and 18, respectively, representing two vehicles passing over the bridge. Magnifying the first peak and the second peak of the strain measurements from sensor 1 and sensor 18 respectively and eliminating the false peaks on the strain difference time histories, the strain difference time histories are shown in Fig. 11(a) and 10(b). The false peak values were found and eliminated with regard to the conclusions about peak value information discussed in Section 2.2, and three smaller peaks were finally found and shown in Fig. 11(a), which
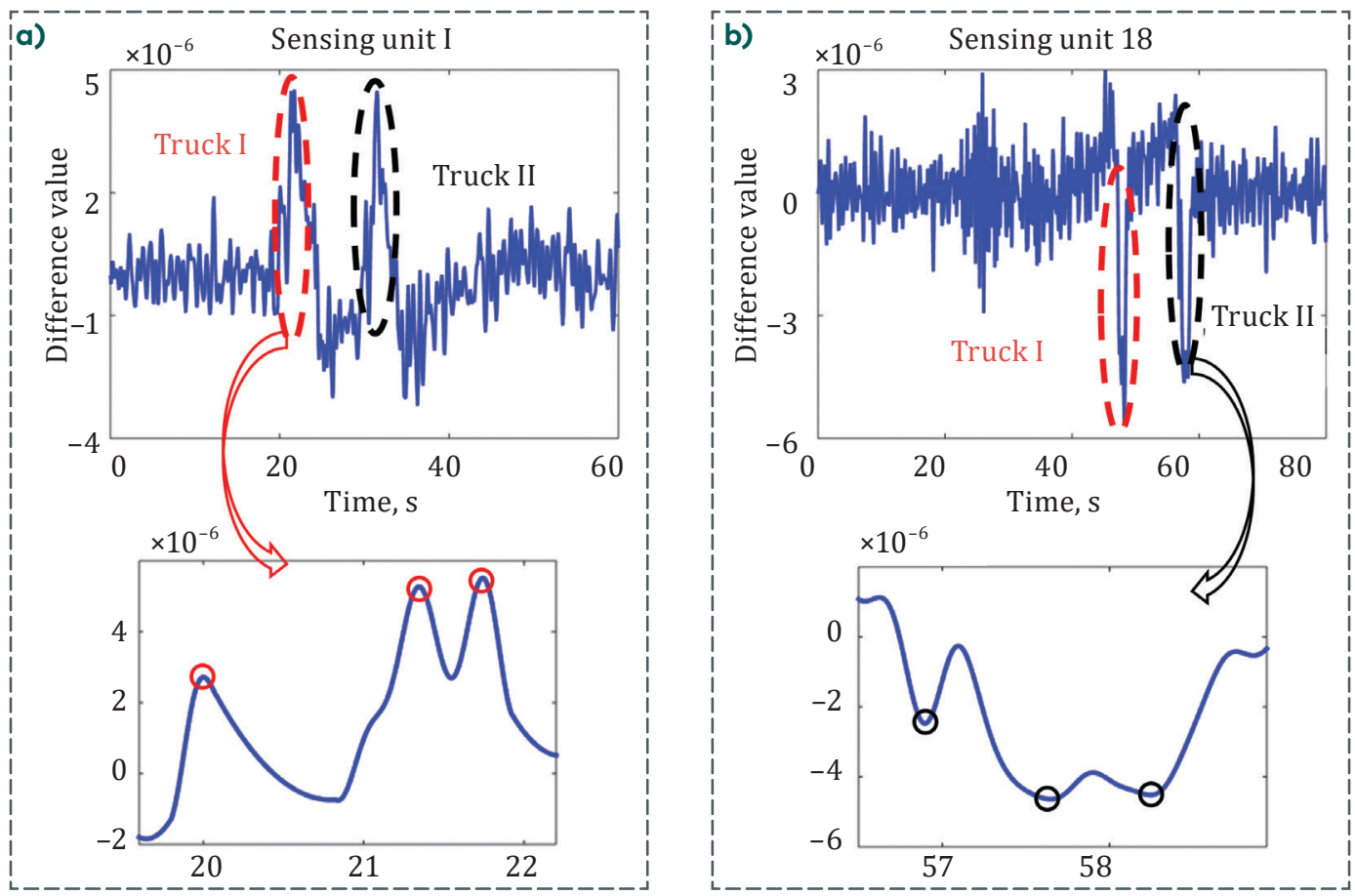

Figure 11. The strain difference time history: (a) sensing unit $1 ;(b)$ sensing unit 18 
illustrates that truck I has three axles. Magnifying the second peak of the strain measurements from sensor 18, three smaller peaks are shown in Fig. 11(b), which illustrates that truck II has three axles.

With Long Gauge Fiber Optic Strain

It is necessary to determine the time corresponding to smaller peaks from Fig. 11(a) and (b), respectively, in order to identify axle weight ratios. Axle weight ratios of the moving vehicles were calculated using Eq. (6), the results are shown in Fig. 12. In this figure, the identified values are compared with the measured values that demonstrate good agreement, which confirms the effectiveness of the proposed method for axel weight ratio identification. The time corresponding to the first peaks of the strain response time histories from all sensors were extracted to estimate the velocity of trucks I and II by Eq. (8), from which the axle spacing of trucks can be identified. The errors of the identified axle spacing for truck I are 3.7\% and $10.4 \%$, for truck II are $4.3 \%$, and $12.2 \%$. Because the axle space between the middle and the rear is $1.35 \mathrm{~m}$, which is very small, the error of the identified second axle spacing is larger than that of the first identified axle spacing.

\subsubsection{GVWs and axle weights identification}

In this sub-section, the vehicle spacing and the loading vehicle for maximum value were estimated in order to determine the axle load pattern based on the axle spacing and the axle weight ratios identified above, and the strain data from all of the long-gauge sensors are necessary for the estimation of these parameters. Firstly, the filtered strain response time histories were given for each sensing unit in Fig. 13(a). However, the strain responses measured by sensors 1 to 3 do not have obvious peaks because the three sensors are located near the supports of the bridge. Based on the filtered strain data and

a)

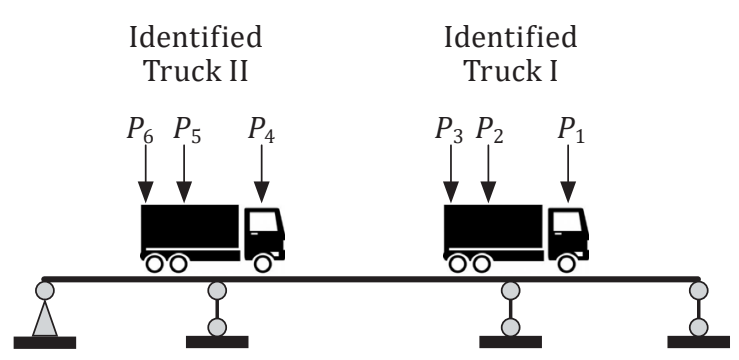

b)

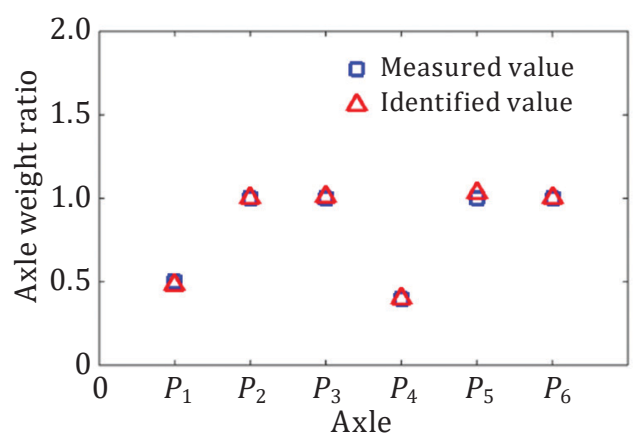

Figure 12. The identified axle weight ratios in the verification test:

(a) identified trucks; (b) identified axle weight ratios 

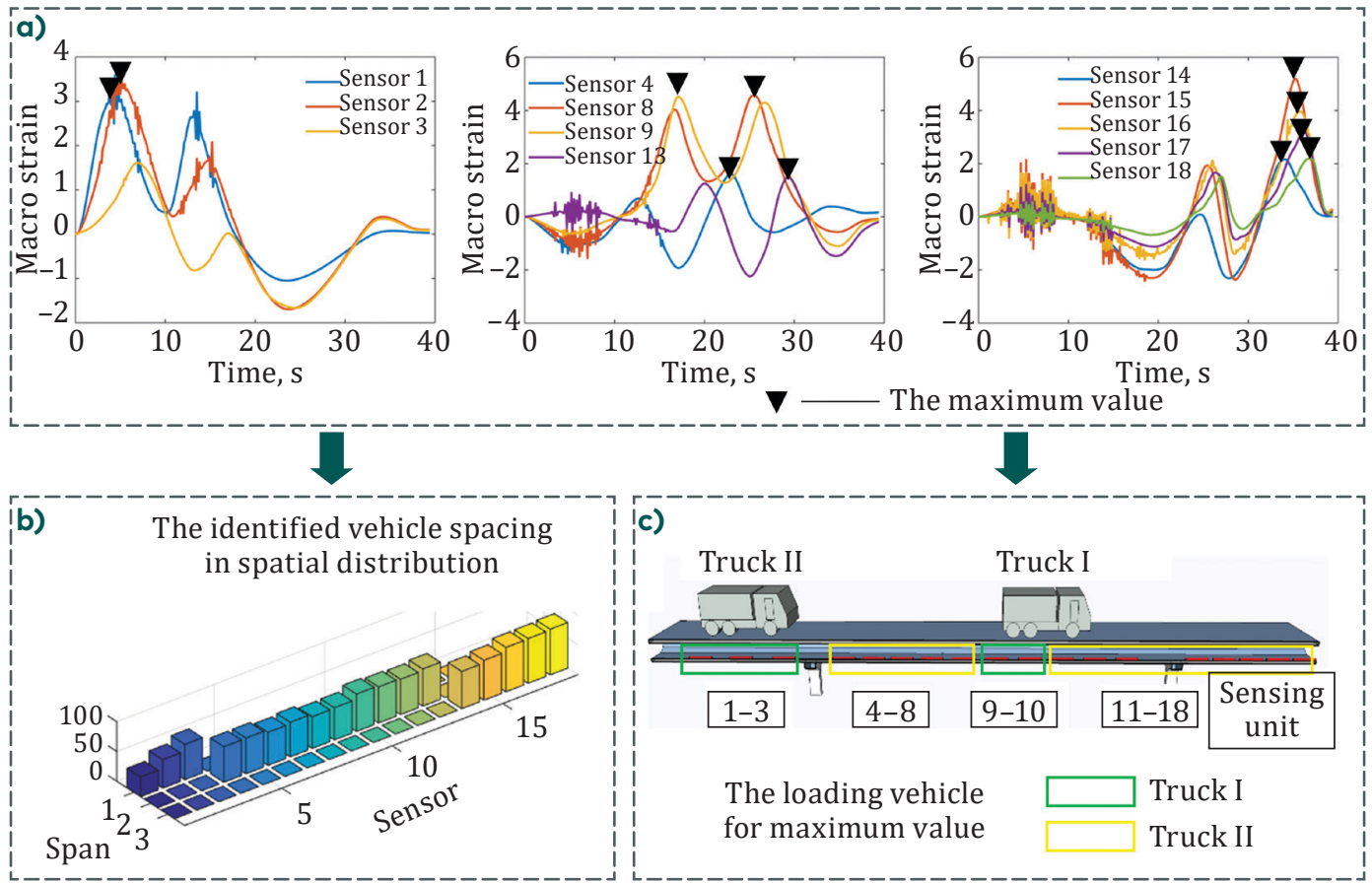

Figure 13. The identified vehicle spacing and loading vehicles for maximum value: (a) the filtered strain data; (b) the identified vehicle spacing in spatial distribution; (c) the identified loading vehicle for the maximum value
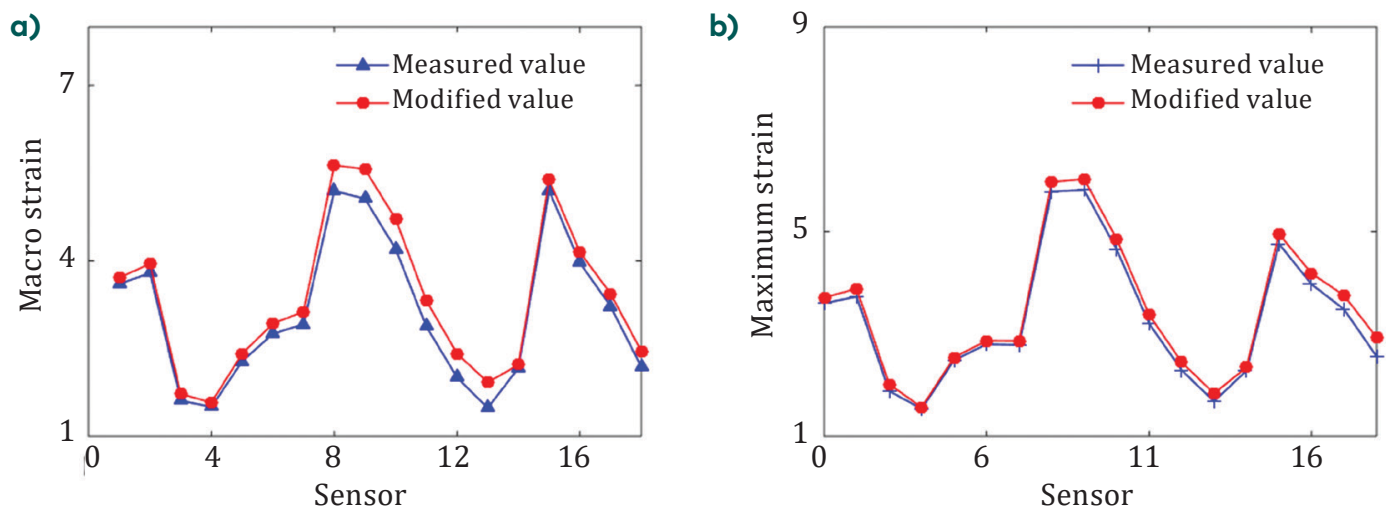

Figure 14. The modified maximum strain: (a) the verification test; (b) the calibration test 
Comparing the modified maximum strain value of each sensing unit in the verification test with the corresponding value in the calibration test, the GVWs of moving vehicles can be calculated, as shown in Fig. 15.

It is known from Fig. 13(c) that the identified results from sensors 1, 2, 3, 9 and 10 are the GVW of truck I, and the other identified results are that of truck II. Fig. 15 (a) and (c) show the identified GVW using the proposed method and the traditional method, respectively. For the proposed method, the identified average GVW value for truck I is $291.13 \mathrm{kN}$, for truck II $-299.79 \mathrm{kN}$, of which the error for truck I is $2.95 \%$ and for truck II $-0.07 \%$. However, within the traditional method, the identified average GVW value for truck I is $284.10 \mathrm{kN}$, for truck II $287.45 \mathrm{kN}$, of which the error for truck I is $5.3 \%$ and for truck II $-4.18 \%$. It may be seen that compared with the traditional method, the identified GVWs of trucks I and II are basically the same as the real values. The
Identification

With Long Gauge

Fiber Optic Strain Sensing
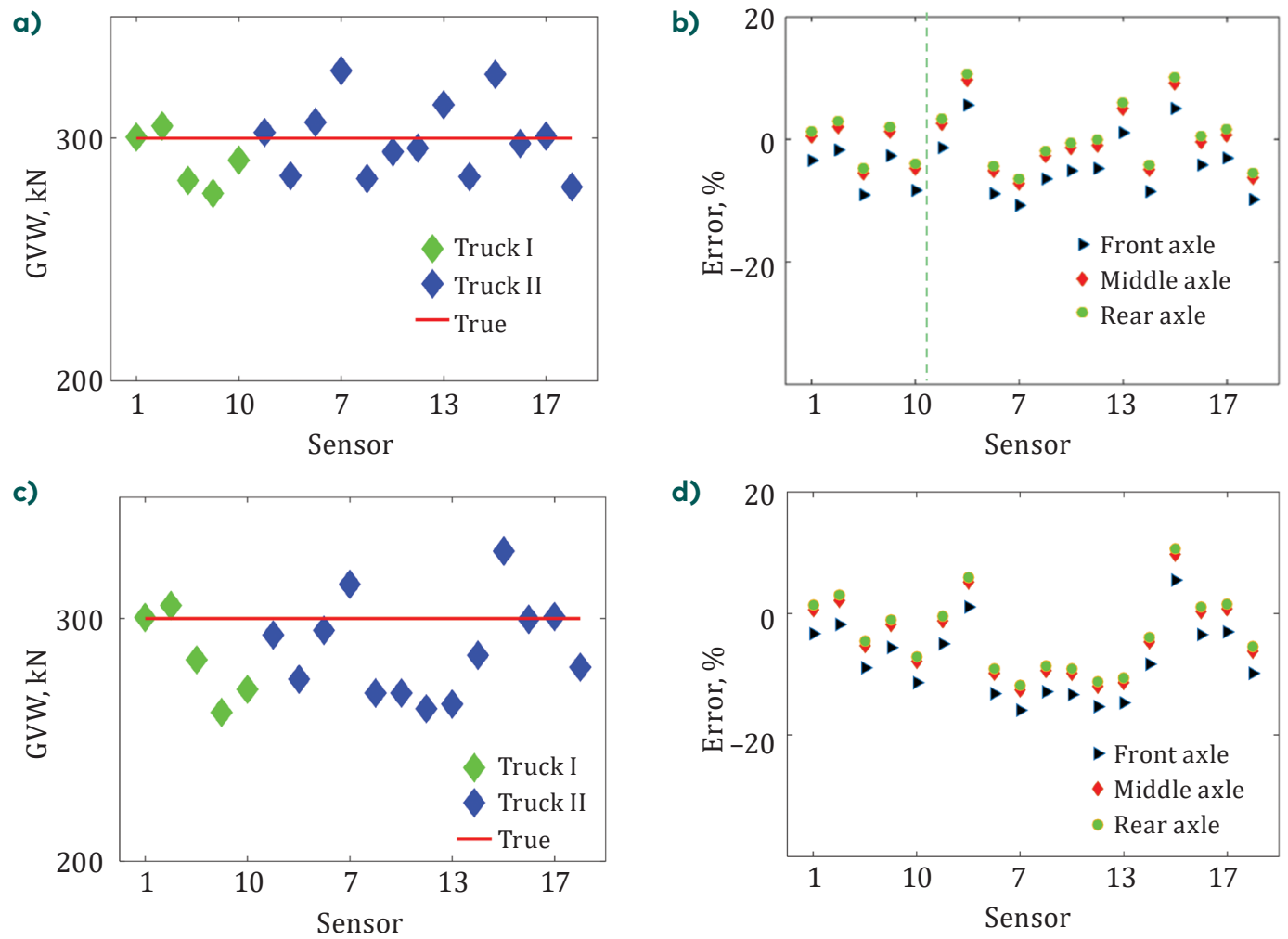

Figure 15. The results identified in the field test: (a) the identified GVWs and (b) the error of the identified axle weight using the proposed method; (c) the identified GVWs and (d) the error of the identified axle weight using the traditional method 
axle weights of truck I and truck II are predicted, and Fig. 15(b) and (d) demonstrate the errors in the identified axle weight of the proposed method and the traditional method, respectively. Within the proposed method, the average error of axle weight identification for the first axle, the middle axle and the rear axle is $4.25 \%, 0.44 \%$ and $0.38 \%$, respectively. But within the traditional method, the average error of axle weight identification for the first axle, the middle axle and the rear axle is $7.75 \%, 4.07 \%$ and $3.28 \%$, respectively. Conclusion can be drawn that the presented method can achieve better results in the identification of moving loads and axle weights.

\section{Conclusions}

A method for moving vehicle load identification using long-gauge strain responses has been presented. The gross vehicle weights (GVWs) and axle weights of the moving vehicles have been calculated by the measured strain data. Numerical analysis was conducted to confirm the feasibility of this method. The field test results with the largest estimation error of $4.25 \%$ show that this method is practical for a fullscale bridge. The following conclusions have been made:

- The strain time histories near the supports are sensitive to axle parameters. They were used to obtain the data on the number of axles, axle velocity, axle spacing and axle weight ratios through the strain difference of the maximum strain.

- The modified maximum strain value caused only by the axle loads was calculated in order to identify the moving vehicle loads. The proposed method first determines the axle load patterns, when the maximum value occurs at different positions on the bridge, and then eliminates the influence of the axle parameters from the maximum value to obtain the modified maximum strain value.

- The proposed method has the advantage of robustness and strong noise-resistant capacity. Comparing the proposed method with the traditional method, the GVWs and axle weights can be identified effectively. It is known from the derivation of the formula presented in this article that the proposed method is not limited to any specific bridge type and can be applied in the conditions, where there are multiple moving vehicles on the bridge.

- More detailed studies will be performed in future, analyzing the effect of vehicle speed on the load identification accuracy in field test, the condition of vehicles in the opposite directions, estimating multi-lane vehicle loads, etc. 


\section{Acknowledgments}

This work was financially supported by the National Key Research and Development Program of China (No.2019YFC1511105), and the National Science Foundation of China under Grant (No. 51908386).

\section{REFERENCES}

Alamandala, S., Prasad, R. L. N. S., Pancharathi, R. K., Pavan, V. D. R., \& Kishore, P. (2021). Study on bridge weigh in motion (BWIM) system for measuring the vehicle parameters based on strain measurement using FBG sensors. Optical Fiber Technology, 61, 102440. https://doi.org/10.1016/j.yofte.2020.102440

Bao, T., Babanajad, S. K., Taylor, T., \& Ansari, F. (2016). Generalized Method and Monitoring Technique for Shear-Strain-Based Bridge Weigh-in-Motion. Journal of Bridge Engineering, 21(1), 04015029. https://doi.org/10.1061/(ASCE)BE.1943-5592.0000782

Bocciolone, M., Bucca, G., Collina, A., \& Comolli, L. (2013). Pantograph-catenary monitoring by means of fibre Bragg grating sensors: Results from tests in an underground line. Mechanical Systems and Signal Processing, 41(1-2), 226-238. https://doi.org/10.1016/j.ymssp.2013.06.030

Caprani, C., OBrien, E. J., \& Blacoe, S. (2013). Vision Systems for Analysis of Congested Traffic. IABSE Conference: Assessment, Upgrading and Refurbishment of Infrastructures, Rotterdam, The Netherlands, 6-8 May 2013, 432-433. https://doi.org/10.2749/222137813806501966

Chan, T. H. T., Yu, L., Law, S. S., \& Yung, T. H. (2001). Moving Force Identification Studies, II: Comparative Studies. Journal of Sound and Vibration, 247(1), 77-95. https://doi.org/10.1006/jsvi.2001.3629

Chen, L., Jiang, Z., Gao, W., \& Zhou, Y. (2020). Identification and adjustment of the pretension deviation in cable-strut tensile structures. KSCE Journal of Civil Engineering, 24(1), 143-152. https://doi.org/10.1007/s12205-020-1473-4

Chen, S-Z., Wu, G., \& Feng, D-C. (2019). Development of a bridge weigh-in-motion method considering the presence of multiple vehicles. Engineering Structures, 191, 724-739. https://doi.org/10.1016/j.engstruct.2019.04.095

Dan, D., Ge, L., \& Yan, X. (2019). Identification of moving loads based on the information fusion of weigh-in-motion system and multiple camera machine vision. Measurement, 144, 155-166. https://doi.org/10.1016/j.measurement.2019.05.042

Dunne, D., O’Brien, E. J., Basu, B., \& Gonzalez, A. (2005). Bridge WIM systems with Nothing on the Road (NOR). International Conference on Weigh-in-motion, 4th, Taipei, Taiwan.

Feng, D., Sun, H., \& Feng, M. Q. (2015). Simultaneous identification of bridge structural parameters and vehicle loads. Computers \& Structures, 157, 76-88. https://doi.org/10.1016/j.compstruc.2015.05.017

Ge, L., Dan, D., Yan, X., \& Zhang, K. (2020). Real time monitoring and evaluation of overturning risk of single-column-pier box-girder bridges based on
Moving Load Identification With Long Gauge Fiber Optic Strain Sensing 
identification of spatial distribution of moving loads. Engineering Structures, 210, 110383. https://doi.org/10.1016/j.engstruct.2020.110383

Gonzalez, A., Dowling, J., OBrien, E. J., \& Žnidarič, A. (2012). Testing of a Bridge Weigh-in-Motion Algorithm Utilizing Multiple Longitudinal Sensor Locations. Journal of Testing and Evaluation, 40(6), 104576. https://doi.org/10.1520/JTE104576

González, A., Rowley, C., \& OBrien, E. J. (2008). A general solution to the identification of moving vehicle forces on a bridge. International Journal for Numerical Methods in Engineering, 75(3), 335-354. https://doi.org/10.1002/nme.2262

He, W., Deng, L., Shi, H., Cai, C. S., \& Yu, Y. (2017). Novel Virtual Simply Supported Beam Method for Detecting the Speed and Axles of Moving Vehicles on Bridges. Journal of Bridge Engineering, 22(4), 04016141. https://doi.org/10.1061/(ASCE)BE.1943-5592.0001019

He, W., Ling T., Obrien, E. J., \& Deng, L. (2019). Virtual axle method for bridge weigh-in-motion systems requiring no axle detector. Journal of Bridge Engineering, 24(9), 04019086. https://doi.org/10.1061/(ASCE)BE.1943-5592.0001474

Jacob, B., \& Feypell-de La Beaumelle, V. (2010). Improving truck safety: Potential of weigh-in-motion technology. Iatss Research, 34(1), 9-15. https://doi.org/10.1016/j.iatssr.2010.06.003

Kalin, J., Žnidarič, A., \& Lavrič, I. (2006). Practical implementation of nothing-on-the-road bridge weigh-in-motion system. 9th International Symposium on Heavy Vehicle Weights and Dimensions, The Pennsylvania State University, Pennsylvania, Pittsburgh, PA, USA.

Law, S. S., \& Chan, T. H. T., Zhu Q. Z., \& Zeng Q. H. (2001). Regularization in moving force identification. Journal of Engineering Mechanics, 127(2), 136-148. https://doi.org/10.1061/(ASCE)0733-9399(2001)127:2(136)

Lee, I., Kwon, S. H, Park, J., \& Oh, T. (2018). The effective near-surface defect identification by dynamic behavior associated with both impact-echo and flexural modes for concrete structures. KSCE Journal of Civil Engineering, 22, 747-754. https://doi.org/10.1007/s12205-017-1433-9

Li, H. L., Lu, Z. R., Liu, J. K., \& Huang, M. (2016). Precise identification of moving vehicular parameters based on improved glowworm swarm optimization algorithm. Inverse Problems in Science and Engineering, 25(5), 694-709. https://doi.org/10.1080/17415977.2016.1191074

Li, S., \& Wu, Z. (2007). Development of Distributed Long-gage Fiber Optic Sensing System for Structural Health Monitoring. Structural Health Monitoring, 6(2), 133-143. https://doi.org/10.1177/1475921706072078

Lu, Z. R., \& Liu, J. K. (2011). Identification of both structural damages in bridge deck and vehicular parameters using measured dynamic responses. Computers \& Structures, 89(13-14), 1397-1405. https://doi.org/10.1016/j.compstruc.2011.03.008

Meng, F., Yu, J., Alaluf, D., Mokrani, B., \& Preumont, A. (2019). Modal flexibility based damage detection for suspension bridge hangers: A number and experimental investigation. Smart Structures and Systems, 23(1), 15-29. https://doi.org/10.12989/sss.2019.23.1.015 
Pan, C. D., Yu, L., \& Liu, H. L. (2017). Identification of moving vehicle forces on bridge structures via moving average Tikhonov regularization. Smart Materials and Structures, 26(8), 085041. https://doi.org/10.1088/1361-665X/aa7a48

Pinkaew, T., \& Asnachinda, P. (2007). Experimental study on the identification of dynamic axle loads of moving vehicles from the bending moments of bridges. Engineering Structures, 29(9), 2282-2293. https://doi.org/10.1016/j.engstruct.2006.11.017

Rahbari, R., Niu, J., Brownjohn, J. M. W., \& Koo, K. Y. (2015). Structural identification of humber bridge for performance prognosis. Smart Structures and Systems, 15(3), 665-682. https://doi.org/10.12989/sss.2015.15.3.665

Shahbaznia, M., Mirzaee, A., \& Dehkordi, M. R. (2020). A new model updating procedure for reliability-based damage and load identification of railway bridges. KSCE Journal of Civil Engineering, 24(3), 890-901. https://doi.org/10.1007/s12205-020-0641-x

Tang, Q., Zhou, J., Xin, J., Zhao, S., \& Zhou, Y. (2020). Autoregressive model-based structural damage identification and localization using convolutional neural networks. KSCE Journal of Civil Engineering, 24(7), 2173-2185. https://doi.org/10.1007/s12205-020-2256-7

Wang, H., Zhu, Q., \& Li, J. (2019). Identification of moving train loads on railway bridge based on strain monitoring. Smart Structures and Systems, 23(3), 263-278. https://doi.org/10.12989/sss.2019.23.3.263

Wu, S. Q., \& Law, S. S. (2001). Vehicle axle load identification on bridge deck with irregular road surface profile. Engineering Structures, 33(2), 591-601. https://doi.org/10.1016/j.engstruct.2010.11.017

Yang, C. Q., Yang, D., He, Y., Wu, Z. S., Xia, Y. F., \& Zhang, Y. F. (2016). Moving Load Identification of Small and Medium-Sized Bridges Based on Distributed Optical Fiber Sensing. International Journal of Structural Stability and Dynamics, 16(4), 1640021. https://doi.org/10.1142/S0219455416400216

Zhang, H., Zhou, Y., \& Quan, L. (2021). Identification of a moving mass on a beam bridge using piezoelectric sensor arrays. Journal of Sound and Vibration, 491, 115754. https://doi.org/10.1016/j.jsv.2020.115754

Zhang, Q., Zhang, J., Duan, W., \& Wu, Z. (2017). Deflection distribution estimation of tied-arch bridges using long-gauge strain measurements. Structural Control and Health Monitoring, 25(3), e2119. https://doi.org/10.1002/stc.2119

Zhang, Q., Xia, Q., Zhang, J., Wu., Z. (2016). Optimal layout of long-gauge sensors for deformation distribution identification. Smart Structures and Systems, 18(3), 389-403. https://doi.org/10.12989/sss.2016.18.3.389

Zhang, Q., \& Zhang, J. (2020). Internal force monitoring and estimation of a long-span ring beam using long-gauge strain sensing. Computer-Aided Civil and Infrastructure Engineering, 36(1), 109-122. https://doi.org/10.1111/mice.12569

Zhao, Z., Uddin, N., \& O’Brien, E. J. (2016). Bridge Weigh-in-Motion Algorithms Based on the Field Calibrated Simulation Model. Journal of Infrastructure Systems, 23(1), 04016021.

https://doi.org/10.1061/(ASCE)IS.1943-555X.0000308 
THE BALTIC JOURNAL OF ROAD AND BRIDGE ENGINEERING $2021 / 16(3)$

Zhu, X. Q., \& Law, S. S. (2006). Moving load identification on multi-span continuous bridges with elastic bearings. Mechanical Systems and Signal Processing, 20(7), 1759-1782. https://doi.org/10.1016/j.ymssp.2005.06.004

Žnidarič, A., Kalin, J., \& Lavrič, I. (2002). Bridge weigh-in-motion measurements on short slab bridges without axle detectors. International Conference on Weigh-In-Motion, Lowa State University, Orlando, Florida. 